\title{
INFLUENCE OF DYNAMIC ANALYSIS METHODS ON SEISMIC RESPONSE OF A BUTTRESS DAM
}

CORNEL ILINCA - Lecturer, PhD, Technical University of Civil Engineering of Bucharest, Faculty of Hydrotechnics, e-mail: cornel@utcb.ro

RĂZVAN VÂRVOREA - PhD student, Technical University of Civil Engineering of Bucharest, Faculty of Hydrotechnics, e-mail: razvan.varvorea@utcb.ro

ADRIAN POPOVICI - Professor, PhD, Technical University of Civil Engineering of Bucharest, Faculty of Hydrotechnics, e-mail: popovici@utcb.ro

\begin{abstract}
The seismic analysis of a buttress dam with $73.50 \mathrm{~m}$ height is performed by the spectral analysis method and the direct time integration method. An accelerogram with $0.1 \mathrm{~g}$ maximum acceleration was applied horizontally, in the upstream - downstream direction, at the bottom of the dam-foundation finite element mesh. The hydrodynamic effect of the reservoir was considered according to the added mass procedure (Westergaard relation). ABAQUS software was used to make the analyses. The same type of finite element C3D20R was used for the mesh of the dam body and of the foundation. The comparison of the results is made on the displacements, the stress state and the sliding stability on the dam-foundation contact in the full reservoir hypothesis. The comprehensive analysis concluded that both methods had provided close results for the considered case study. The spectral analysis method revealed itself to be more conservative compared to the direct time integration method.
\end{abstract}

Keywords: dams, earthquakes, dynamic analyses, stress

\section{Introduction}

Edward Wilson a well-known Professor of seismic analysis of structures from the University of California wrote (August, 28th 2013, www.edwilson.org) the following comments on seismic analysis methods: "Convince engineers that the Response Spectrum Method produces very poor results. Convince engineers that it is easy to conduct Linear Dynamic Response Analysis".

The scope of this paper is to check this opinion in the case of concrete dams, structures known as having a complex seismic response because of the interaction of the structure with water from the reservoir and the foundation area [6], [7], [8].

The seismic response of the Gura Râului dam, a buttress dam with 73.50 m maximum height, is evaluated comparatively by means of the Response Spectrum Method and the Direct Time Integration of Motion Equations [1], [4].

The seismic action with a PGA of $0.1 \mathrm{~g}$ consisted of a horizontal component of the accelerogram recorded at Focsani seismic station during the August 30th 1986 Vrancea earthquake.

The horizontal component with a PGA of $0.271 \mathrm{~g}$ (g-gravity) of the recorded accelerogram at Focsani INCERC seismic station during the August 30th 1986 Vrancea earthquake, scaled to $0.1 \mathrm{~g}$ maximum acceleration was used to act on Gura Râului dam. The subsoil of the seismic station has a geologic profile close to that of the dam site. The accelerogram was applied at the bottom of the dam-foundation system finite element mesh horizontally, on the upstreamdownstream direction.

The influence of the reservoir on the seismic response was taken into account by the added mass procedure. The added masses were computed according to the Westergaard relation. 
The analysis was performed with ABAQUS software, the solid elements type C3D20R were used for the mesh of the dam-foundation system. The linear elastic behavior of the materials was accepted in all analyses [3].

The comparison of results in the dam seismic analysis for those two methods mentioned above is performed in displacements, stress state and sliding stability on the dam-foundation contact in the full reservoir hypothesis.

\section{Short description of the Gura Râului dam}

Gura Râului dam, commissioned in 1974, is a buttress dam with $73.50 \mathrm{~m}$ maximum height (Fig.1). [2], [5].
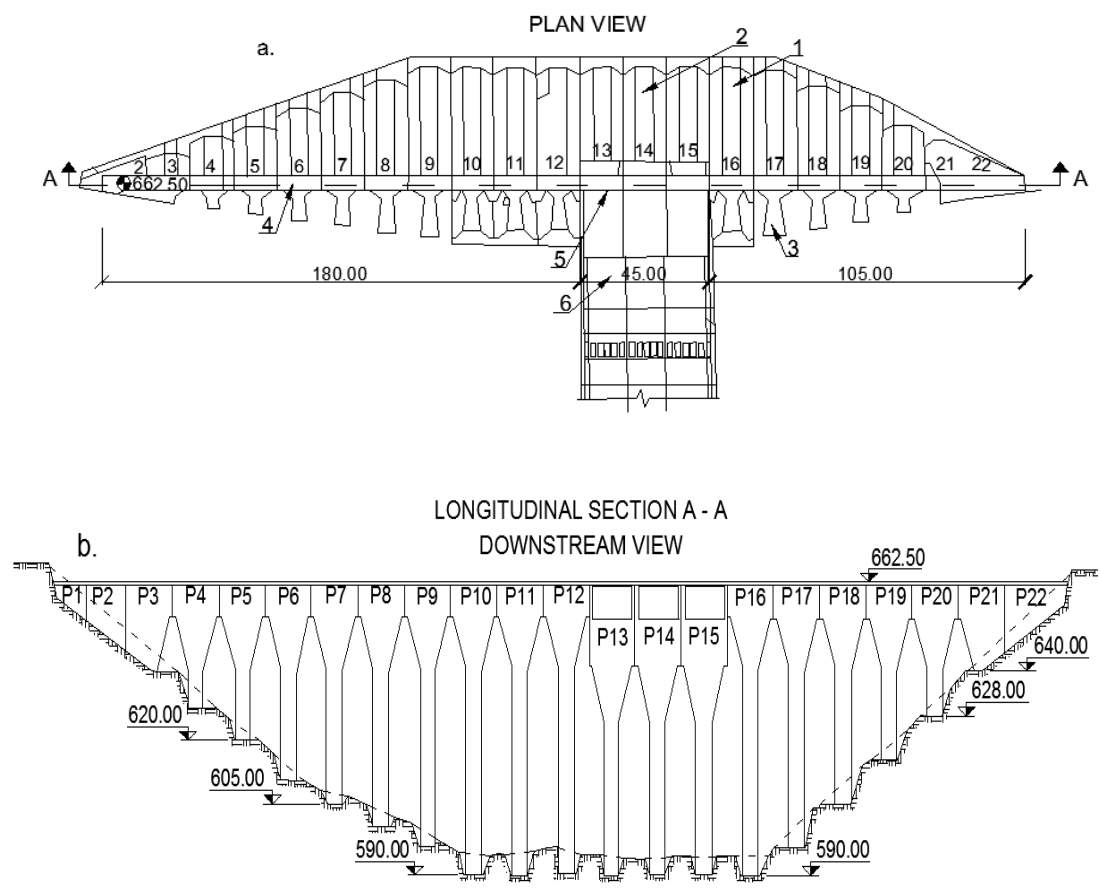

Fig. 1 - Gura Râului dam layout (a) and longitudinal section through the dam axis (b): 1 - non-overflow block, 2 - overflow block, 3 - buttress, 4 - crest, 5 - overflow span, 6 - stilling basin

The dam is located within the Sub-Carpathian Depression of Sibiu County. The rock from the dam foundation consists generally by gneiss with rare amphibolite intercalations and pegmatite intrusions. The friction coefficient to sliding on the dam-foundation contact was evaluated at 0.70 .

Gura Râului development has multiple uses as follows: water supply of Sibiu city and neighboring localities $(1440 \mathrm{l} / \mathrm{s}$ ), production of hydroelectric energy (hydropower plant with $\mathrm{Pi}=3700 \mathrm{~kW}$ located downstream of the dam) and flood control [2].

The main characteristics of the development can be summarized as follows (Fig. 2):

- maximum height of the dam.... $73.50 \mathrm{~m}$

- crest length $328.00 \mathrm{~m}$

- crest width. $6.20 \mathrm{~m}$

- base width $57.40 \mathrm{~m}$

- upstream and downstream slopes. $1: 0.57$ and $1: 0.28$

- thickness of buttress (variable). $.4 .50 \ldots 8.00 \mathrm{~m}$

- concrete volume of the dam body $.300500 \mathrm{~m}^{3}$

- capacity of discharge works $.832 \mathrm{~m}^{3} / \mathrm{s}$

- reservoir volume at NRL $.15 \cdot 106 \mathrm{~m}^{3}$ 
The dam blocks are with polygonal heads and buttresses with variable thickness in horizontal cross-section, increasing from the contact polygonal head-buttress to downstream. This innovative solution proposed by Priscu - Popovici [1], applied for the first time in this field led to significant savings in dam concrete volume evaluated at about $14 \%$ compared to the usual solution with buttresses having constant thickness.

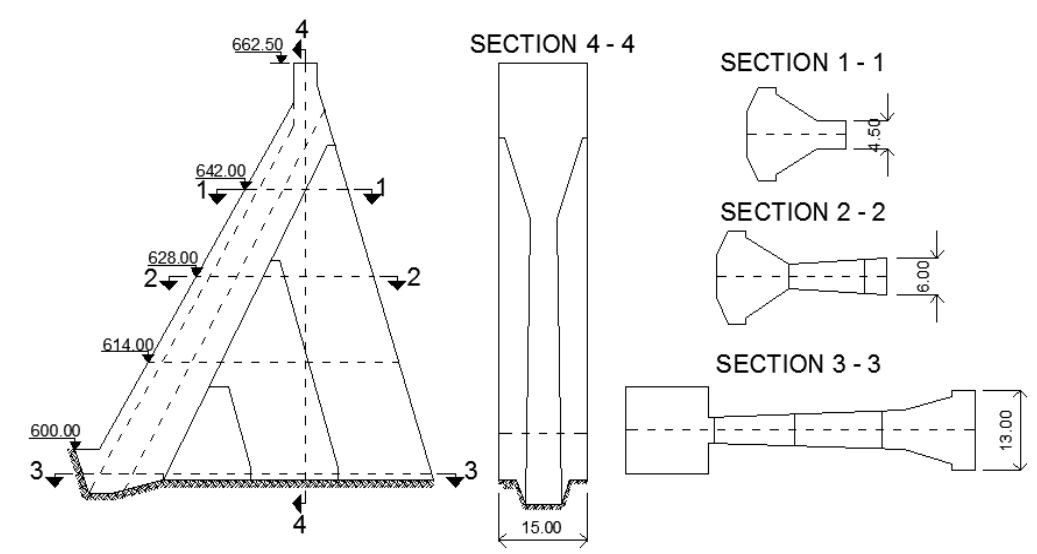

Fig. 2 - Representative cross sections through block no. 11

A number of 19 non-overflow blocks and 3 overflow blocks make up the retention. Water tightening between the blocks within the area of the polygonal head units was achieved by means of a $1.5 \mathrm{~mm}$ thick copper steel sheet doubled by a M35 type polyvinyl band.

The dam spillway consists of three free overflow openings located in central blocks. The total length of the surface spillway is $39 \mathrm{~m}$ with maximum discharge capacity of $800 \mathrm{~m} 3 / \mathrm{s}$. The bottom outlets consist of two pipes with $1000 \mathrm{~mm}$ diameter having together a total discharge capacity of $32 \mathrm{~m} 3 / \mathrm{s}$ with the reservoir at Normal Retention Level (NRL).

The energy of the discharged water from the reservoir is dissipated in a battery consisting of two stilling basins located at the dam downstream heel and having $34+18=52 \mathrm{~m}$ total length.

The foundation sealing was carried out by a grout curtain consisting of two rows of injected drillings at $1.50 \mathrm{~m}$ span, with maximum depth of $45 \mathrm{~m}$ for the upstream row and $40 \mathrm{~m}$ for the downstream row. In order to discharge the uplift pressure acting into the dam foundation, downstream of the grout curtain a row of $30 \mathrm{~m}$ deep draining drillings displayed by two for each block was provided.

According to the Romanian national regulations, the dam is classified as the second class in terms of the economic importance and in the category B in terms of the collapsing risk. Thus, this dam requires a special monitoring during its lifetime.

In order to achieve this provision, the dam-foundation unitary system was equipped with several monitoring devices (4 direct pendulums, 2 inverted pendulums, 7 rock meters with 3 rods, piezometer drillings, hydrometers, telepress meters etc.). The monitoring activity, accompanied by visual inspections, ensures the proper surveillance of the dam behavior. It should be mentioned that the dam has behaved normally in terms of displacements, stresses, and seepage during the entire operation, which started in 1974.

\section{Mathematical models and input data}

The block no. 11 (Fig. 2) was selected to be computed to OBE seismic action.

In compliance with the Seismic Hazard Map of Romania the dam site is located in an area with $\mathrm{PGA}=0.20 \mathrm{~g}(\mathrm{PGA}-$ Peak Ground Acceleration) and period corner of $0.7 \mathrm{~s}$.

Table 2-1 from NP 076-2013 sets that for dams classified in the II class as importance and B category as collapsing risk OBE (Operation Basis Earthquake) is 0.28 PGA but no less than 
$0.10 \mathrm{~g}$. Consequently, the dam was computed to the action of an earthquake with $0.10 \mathrm{~g}$ maximum acceleration.

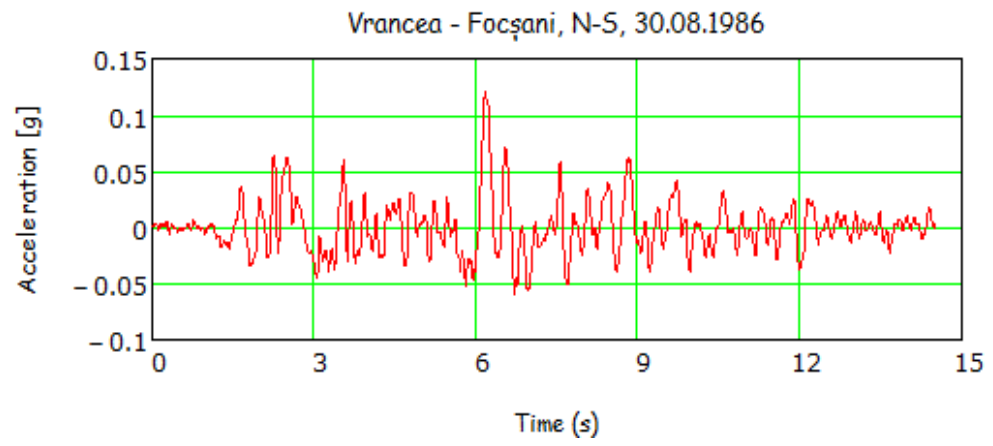

Fig. 3 - N-S component of recorded accelerogram at Focsani INCERC station during the $30^{\text {th }}$ August 1986

Vrancea Earthquake

The seismic action consisting of N-S component of recorded accelerogram at Focsani INCERC station during the 30th August 1986 Vrancea Earthquake (Fig. 3) was applied at the bottom of the dam-foundation finite element mesh system, horizontally, upstream-downstream direction.

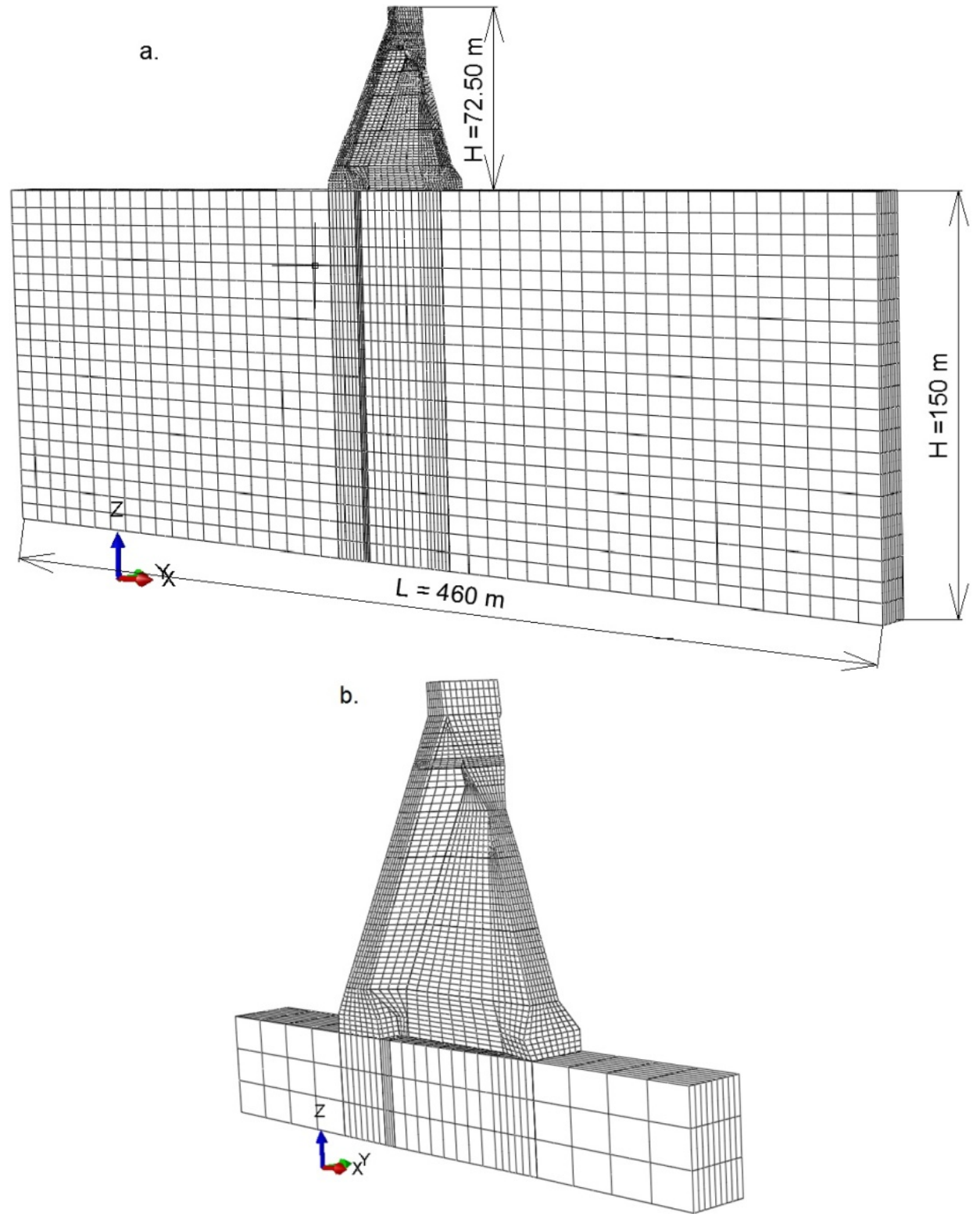

Fig. 4 - Finite element mesh of dam - foundation system: general (a) and dam detail (b) 
The finite element mesh is illustrated in Figure 4. Quadratic hexagonal finite elements type C3D20R from ABAQUS software library were used to perform mesh. In Table 1 are given some data on the finite element mesh.

Table 1

Data on finite element mesh

\begin{tabular}{|c|c|c|}
\hline Nodes - & $\begin{array}{c}\text { Total number } \\
\text { of nodes }\end{array}$ & $\begin{array}{c}\text { Total number of } \\
\text { finite elements }\end{array}$ \\
\hline Dam & 67118 & 12835 \\
\hline Foundation & 73742 & 15260 \\
\hline
\end{tabular}

C3D20R is a three-dimensional solid element with 20 nodes and 3 degrees of freedom in each node. It may be degenerated to an element with 9 nodes. This element is a general-purpose quadratic brick element, with reduced integration points $(2 \times 2 \times 2$ integration points). The reduced integration uses a lower-order integration to form the element stiffness but reduces running time, especially in three dimensions. The mass matrix and the distributed loadings use full integration.

The seismic response spectrum was computed from the accelerogram given in Figure 3, using a well-known relation with convolution integral:

Respectively $\quad \operatorname{Sd}(v, \omega)=\frac{S_{v}(\mathrm{v}, \omega)}{\omega}=\frac{S_{a}(\mathrm{v}, \omega)}{\omega^{2}}$

$$
|\delta(t)|_{\text {max }}=-\frac{1}{\omega}\left|\int_{0}^{t} \ddot{\mathrm{u}}(\tau) e^{-v \omega(t-\tau)} \sin \omega(t-\tau) d \tau\right|_{\max }
$$

Where $|\delta(t)|_{\max }$ is the maximum value (spectral) of the seismic response in displacements;

$\omega$ - circular eigenfrequency of the oscillator $\left(\frac{\mathrm{rad}}{\mathrm{s}}\right)$;

$\ddot{\mathrm{u}}(\tau)$ - accelerogram of the earthquake;

$v$ - oscillator fraction of the critical damping;

$\mathrm{Sd}, \mathrm{Sv}, \mathrm{Sa}-$ spectral values of the response in relative displacements, relative velocities and, absolute accelerations respectively.

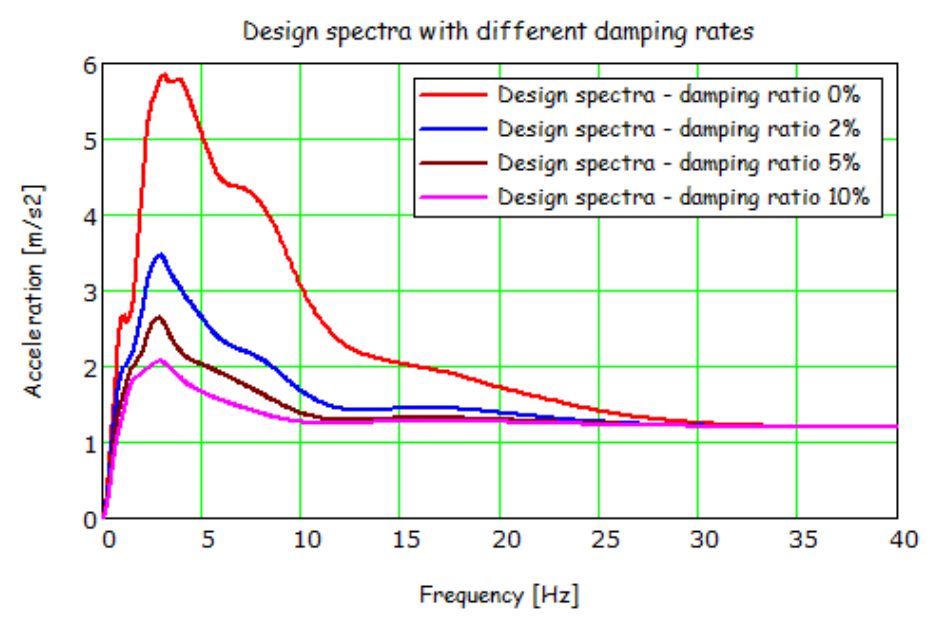

Fig. 5 - Design spectra computed from the NS component of the accelerogram presented in figure 3

Design spectra were obtained by smoothing the values from the seismic response spectra according to the rule of the least squares. The design spectra for $v$ equal to $0.00,0.02,0.05$, and 0.10 are presented in Figure 5. The seismic analysis of the dam was performed for $v=0.05$. This value is recommended in literature, resulting from several in dam site dynamic investigations.

The material characteristics of the dam - foundation system are given in Table 2. The materials were considered homogeneous, isotropic and linear elastic behavior. 
Material characteristics of the dam - foundation system

\begin{tabular}{|c|c|c|}
\hline Materials & Concrete & $\begin{array}{c}\text { Rock } \\
\text { foundation }\end{array}$ \\
\hline Mroperties & 2400 & - \\
\hline Static Poisson coefficient & 0.16 & 0.26 \\
\hline Dynamic Poisson coefficient & 0.22 & - \\
\hline Static Young modulus (MPa) & 24000 & 20000 \\
\hline Dynamic Young modulus (MPa) & 32400 & - \\
\hline
\end{tabular}

The effect of water in the seismic response was considered by the added mass procedure. The definition of the added mass $[\mathrm{Mh}]$ acting on the normal direction in the point of application is as follows:

$$
\left\{\mathrm{P}_{\mathrm{h}}(\mathrm{t})\right\}=-\left[\mathrm{M}_{\mathrm{h}}\right]\left\{\ddot{\mathrm{u}}+\ddot{\delta}_{\mathrm{r}}\right\}_{\mathrm{n}}
$$

where $\{\mathrm{Ph}(\mathrm{t})\}$ is the hydrodynamic force in the reference point and $\{\ddot{\mathrm{u}}+\delta \mathrm{r}\} \mathrm{n}$ is the total acceleration response to the normal direction at surface in the reference point.

This means that added mass as value corresponds with the hydrodynamic force generated by a unitary acceleration on the normal direction at surface in the reference point.

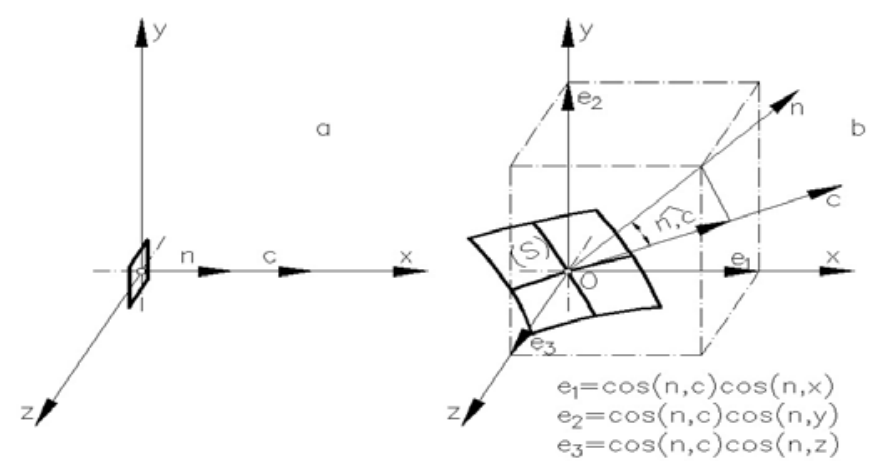

Fig. 6 - Assessment of added masses

In the general case when the directions of the normal to surface, of the earthquake and of the structure degrees of freedom are different, the added mass computed according to relation (3) must be projected successively on earthquake direction and on the structure degrees of freedom (Fig. 6). The dynamic equilibrium equations are written as follows:

$$
[[\mathrm{M}]+[\mathrm{Mh}][\mathrm{rcn}][\mathrm{rn}, \mathrm{x}, \mathrm{y}, \mathrm{z}]]\{\ddot{\delta} \mathrm{r}\}+[\mathrm{C}]\{\dot{\delta} \mathrm{r}\}+[\mathrm{K}]\{\delta \mathrm{r}\}=-[[\mathrm{M}]+[\mathrm{Mh}][\mathrm{rcn}][\mathrm{rn}, \mathrm{x}, \mathrm{y}, \mathrm{z}]]\{\mathrm{r}\} \ddot{\mathrm{u}}
$$

where $[\mathrm{rcn}]$ has the dimensions equal with the number of the degrees of freedom of the system and contains on the diagonal the cosine directors between the normal to surface in the nodes of the mesh and earthquake direction;

$[\mathrm{rn}, \mathrm{x}, \mathrm{y}, \mathrm{z}]$ has dimensions corresponding to the number of the degrees of freedom of the system and contains on the diagonal the cosine directors between the normal to surface in the nodes of the mesh and directions of the system degrees of freedom.

The boundary conditions in the static and spectral analyses consisted in the displacement blockage in $\mathrm{x}, \mathrm{y}, \mathrm{z}$ directions for all nodes located on the lateral faces and the bottom of the foundation and in the y direction of the bank, bank lateral faces of the profile polygonal head.

In the direct time integration the accelerogram was applied at the bottom of the mesh on $x$ direction. The displacements on $\mathrm{y}, \mathrm{z}$ directions at the bottom of the mesh, $\mathrm{y}$ directions on the bank, bank lateral faces of the mesh (dam plate and foundation) and $\mathrm{x}, \mathrm{y}, \mathrm{z}$ directions on upstream, downstream lateral faces of the foundation respectively were blocked.

The time step $(\Delta \mathrm{t})$ in direct time integration was constant and equal to $0.01 \mathrm{~s}$. The response accelerations during a time step were computed using an implicit scheme by solving for dynamic response parameters at time $t+\Delta t$ based not only on values at $t$ but also on these same quantities 
at $\mathrm{t}+\Delta \mathrm{t}$. But because they are implicit, the nonlinear equations must be solved. The static loads and the seismic action were applied successively in distinct steps: dead load (step 1), hydrostatic pressure (step 2), uplift pressure under polygonal head (step 3) and seismic action (step 4).

In the direct time integration analysis, the damping matrix $[\mathrm{C}]$ was evaluated as a function of the mass matrix $[\mathrm{M}]$ and stiffness matrix $[\mathrm{K}]$ in compliance with the linear Rayleigh relation:

$$
[\mathrm{C}]=\alpha[\mathrm{M}]+\beta[\mathrm{K}]
$$

where $\alpha$ and $\beta$ coefficients were evaluated for $v=5 \%$ in first two mode shapes in full reservoir hypothesis $(\alpha=1.402$ and $\beta=0.00158)$.

\section{Results in free vibration analysis}

In Table 3 the first six circular eigenfrequencies $(\omega, \mathrm{rad} / \mathrm{s})$ eigenfrequencies $(\mathrm{f}, \mathrm{Hz})$ and eigenperiods $(\mathrm{T}, \mathrm{s})$ of the dam profile are presented in both empty and full reservoir hypotheses.

Free vibration characteristics

\begin{tabular}{|c|c|c|c|c|c|c|}
\hline \multirow{2}{*}{$\begin{array}{c}\text { Mode } \\
\text { number }\end{array}$} & \multicolumn{3}{|c|}{ Empty reservoir } & \multicolumn{3}{c|}{ Full reservoir (NRL level) } \\
\cline { 2 - 7 } & \multicolumn{2}{|c|}{ Eigenfrequency } & Period & \multicolumn{2}{c|}{ Eigenfrequency } & Period \\
\cline { 2 - 7 } & $\omega(\mathrm{rad} / \mathrm{s})$ & $\mathrm{f}(\mathrm{Hz})$ & $\mathrm{T}(\mathrm{s})$ & $\omega(\mathrm{rad} / \mathrm{s})$ & $\mathrm{f}(\mathrm{Hz})$ & $\mathrm{T}(\mathrm{s})$ \\
\hline 1 & 30.4 & 4.834 & 0.207 & 21.0 & 3.343 & 0.299 \\
\hline 2 & 47.0 & 7.492 & 0.133 & 42.4 & 6.751 & 0.148 \\
\hline 3 & 59.9 & 9.533 & 0.105 & 45.7 & 7.275 & 0.137 \\
\hline 4 & 64.6 & 10.280 & 0.097 & 46.3 & 7.375 & 0.136 \\
\hline 5 & 91.7 & 14.595 & 0.069 & 71.6 & 11.397 & 0.088 \\
\hline 6 & 107.2 & 17.069 & 0.059 & 85.2 & 13.566 & 0.074 \\
\hline
\end{tabular}

In Figure 7 are illustrated first six lowest mode shapes in full reservoir hypothesis.

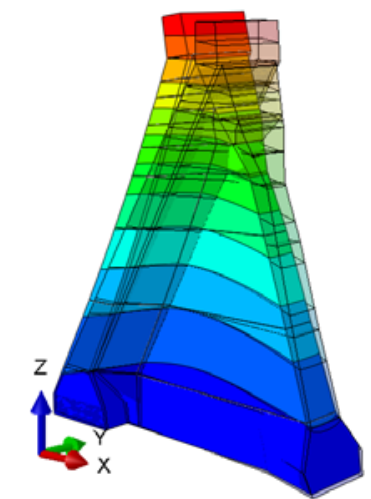

$\mathrm{T}_{1}=0.299 \mathrm{~s}$

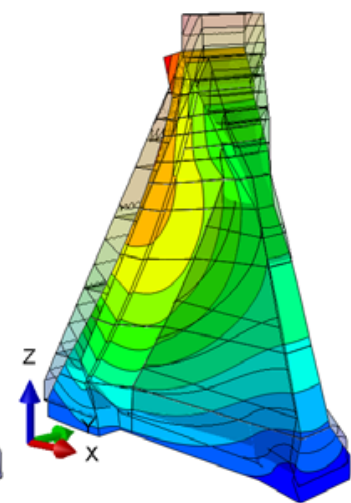

$\mathrm{T}_{2}=0.148 \mathrm{~s}$

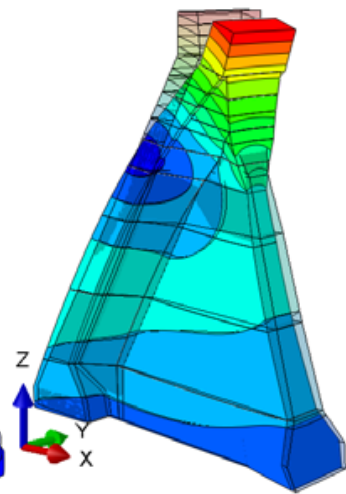

$\mathrm{T}_{3}=0.137 \mathrm{~s}$

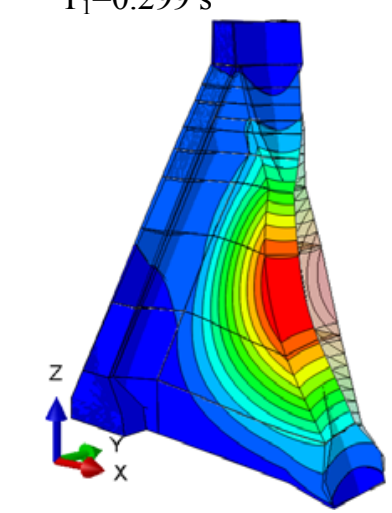

$\mathrm{T}_{4}=0.136 \mathrm{~s}$

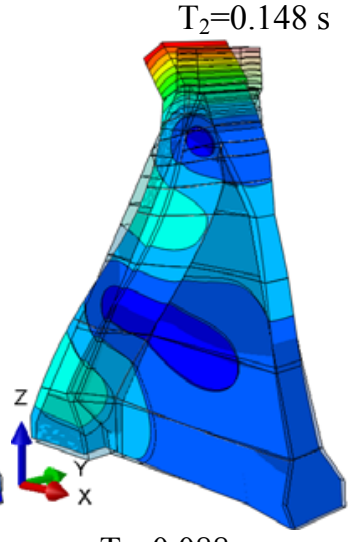

$\mathrm{T}_{5}=0.088 \mathrm{~s}$

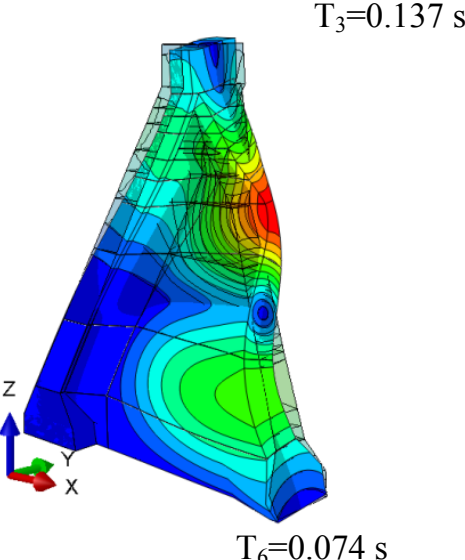

Fig. 7 - Gura Râului dam - first six lowest mode shapes in full reservoir hypothesis (reservoir level at NRL)

It should be noted that Gura Râului buttress dam is classified in the field of rigid structures. The fundamental dam mode is developed mainly on the horizontal upstream - downstream direction 
(x axis). The second mode in the empty reservoir hypothesis and the fourth mode in the full reservoir hypothesis are developed horizontally along the dam crest (bank - bank) modeling the free vibration of the dam buttress as a plate (y direction). The reservoir effect led to the increase of the dam fundamental period with $44 \%$ compared to the empty reservoir $(0.299 \mathrm{~s}$ versus 0.207 $\mathrm{s}$ ), but the profile remains in the same domain of rigid structures.

The participation factors in six lowest mode shapes are given in Table 4 . The participation factor for a mode $\mathrm{k}$ in direction $\mathrm{i}$ is a variable which indicates how strong the global $\mathrm{x}, \mathrm{y}, \mathrm{z}$ translation is about one of the three axes represented in the eigenvector of that mode. For instance, the fundamental mode is important on $\mathrm{x}$ axis (horizontal upstream - downstream direction)

Table 4

Eigenmodes and participation factor (empty and full reservoir)

\begin{tabular}{|c|c|c|c|c|c|c|c|c|c|c|c|}
\hline \multicolumn{6}{|c|}{ Empty reservoir } & \multicolumn{6}{|c|}{ Full reservoir } \\
\hline \multirow{2}{*}{$\begin{array}{l}\dot{0} \\
\dot{z} \\
\dot{0} \\
\dot{0}\end{array}$} & \multirow{2}{*}{$\begin{array}{c}\begin{array}{c}\text { Natural } \\
\text { frequency }\end{array} \\
{[\mathrm{Hz}]}\end{array}$} & \multirow{2}{*}{$\begin{array}{c}\text { Eigenperiods } \\
{[\mathrm{s}]}\end{array}$} & \multicolumn{3}{|c|}{ Participation factor } & \multirow{2}{*}{$\begin{array}{l}\dot{0} \\
\dot{z} \\
\dot{0} \\
\dot{\Sigma}\end{array}$} & \multirow{2}{*}{$\begin{array}{c}\begin{array}{c}\text { Natural } \\
\text { frequency }\end{array} \\
{[\mathrm{Hz}]}\end{array}$} & \multirow{2}{*}{$\begin{array}{c}\text { Eigenperiods } \\
{[\mathrm{s}]}\end{array}$} & \multicolumn{3}{|c|}{ Participation factor } \\
\hline & & & $\mathrm{x}$ & $\mathrm{y}$ & $\mathrm{z}$ & & & & $\mathrm{x}$ & $\mathrm{y}$ & $\mathrm{z}$ \\
\hline 1 & 4.834 & 0.207 & 2.15 & 0 & -0.20 & 1 & 3.343 & 0.299 & -7516 & 0 & -719 \\
\hline 2 & 7.492 & 0.133 & 0 & 2.05 & 0 & 2 & 6.751 & 0.148 & 1596 & 0 & -8804 \\
\hline 3 & 9.533 & 0.105 & 0.43 & 0 & 1.46 & 3 & 7.275 & 0.137 & -4467 & 8 & -2273 \\
\hline 4 & 10.28 & 0.097 & -1.67 & 0 & 1.39 & 4 & 7.375 & 0.136 & -11 & -3142 & -7 \\
\hline 5 & 14.60 & 0.069 & 0 & -0.43 & 0 & 5 & 11.40 & 0.088 & -2403 & 0 & 812 \\
\hline 6 & 17.07 & 0.059 & 0 & -0.93 & 0 & 6 & 13.57 & 0.074 & 1 & -1040 & 1 \\
\hline
\end{tabular}

\section{Analysis Results by response spectrum method}

Response spectrum analysis provides an inexpensive approach to estimating the peak response of a structure subjected to base motion: the simultaneous motion of all nodes fixed with boundary conditions.

The maximum dam displacements and stresses $\left|R_{i}\right|_{\max }$ were computed from "m" (m=25) representative peak modal responses using the square root of the sum of the squares (SRSS):

$$
\left|R_{i}\right|_{\max }=\left(\sum_{k=1}^{m}\left|\left(R_{i}\right)_{k}^{\max }\right|^{2}\right)^{1 / 2}
$$

where index $\mathrm{i}$ is referring to the degree of freedom and $\mathrm{k}$ to the eigenmode.
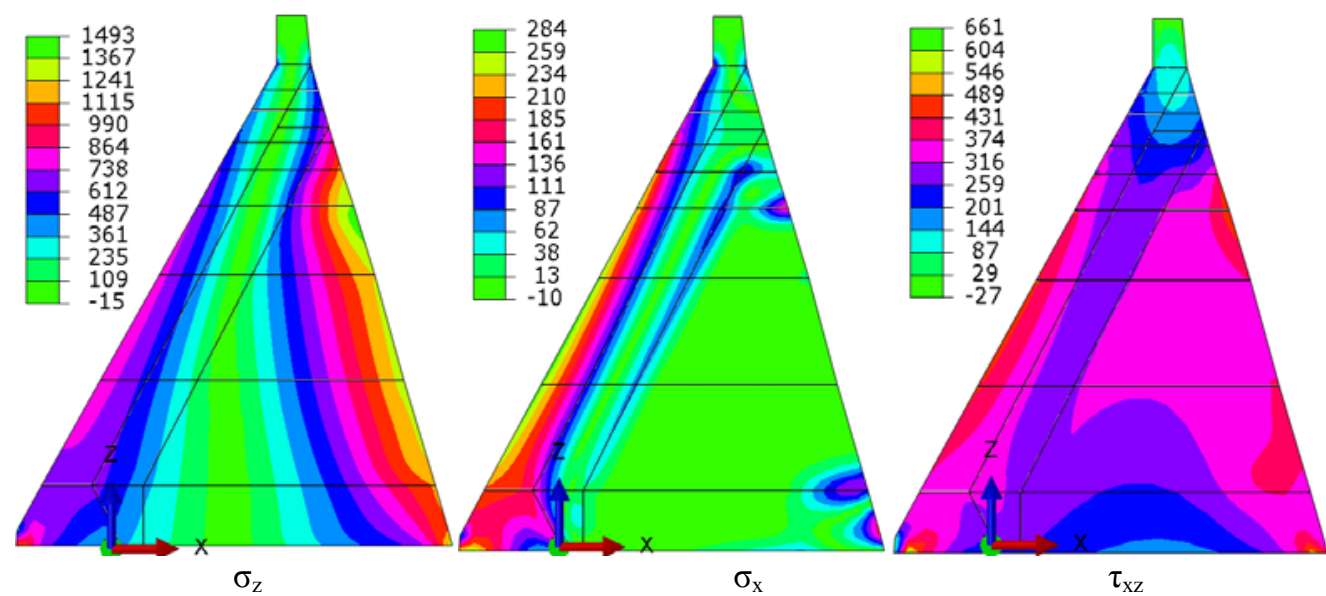

Fig. $8-\sigma_{z}, \sigma_{x}$ and $\tau_{x z}$ contour lines in the central section of the profile resulted in spectral analysis, full reservoir $(\mathrm{kPa})$ 
In Figure $8 \sigma \mathrm{z}, \sigma \mathrm{x}$ and $\tau \mathrm{xz}$ contour lines are illustrated in $\mathrm{kPa}$ in the central section of the profile resulted in the spectral analysis, full reservoir hypothesis. The maximum vertical stress $(\sigma \mathrm{z})$ reaches maximum value of $1277 \mathrm{kPa}$ at downstream face. The maximum shear stress reaches maximum value of $489 \mathrm{kPa}$ at downstream dam heel. The alternative maximum displacement on upstream-downstream horizontal direction computed by the spectral analysis reaches $\pm 9 \mathrm{~mm}$ at crest. On the vertical direction it reaches $\pm 2 \mathrm{~mm}$.

The variations in elevation of $\sigma \mathrm{z}$ and $\tau \mathrm{xz}$ resulted in the spectral analysis, full reservoir case, at upstream and downstream faces of the profile are illustrated in Figure 9.

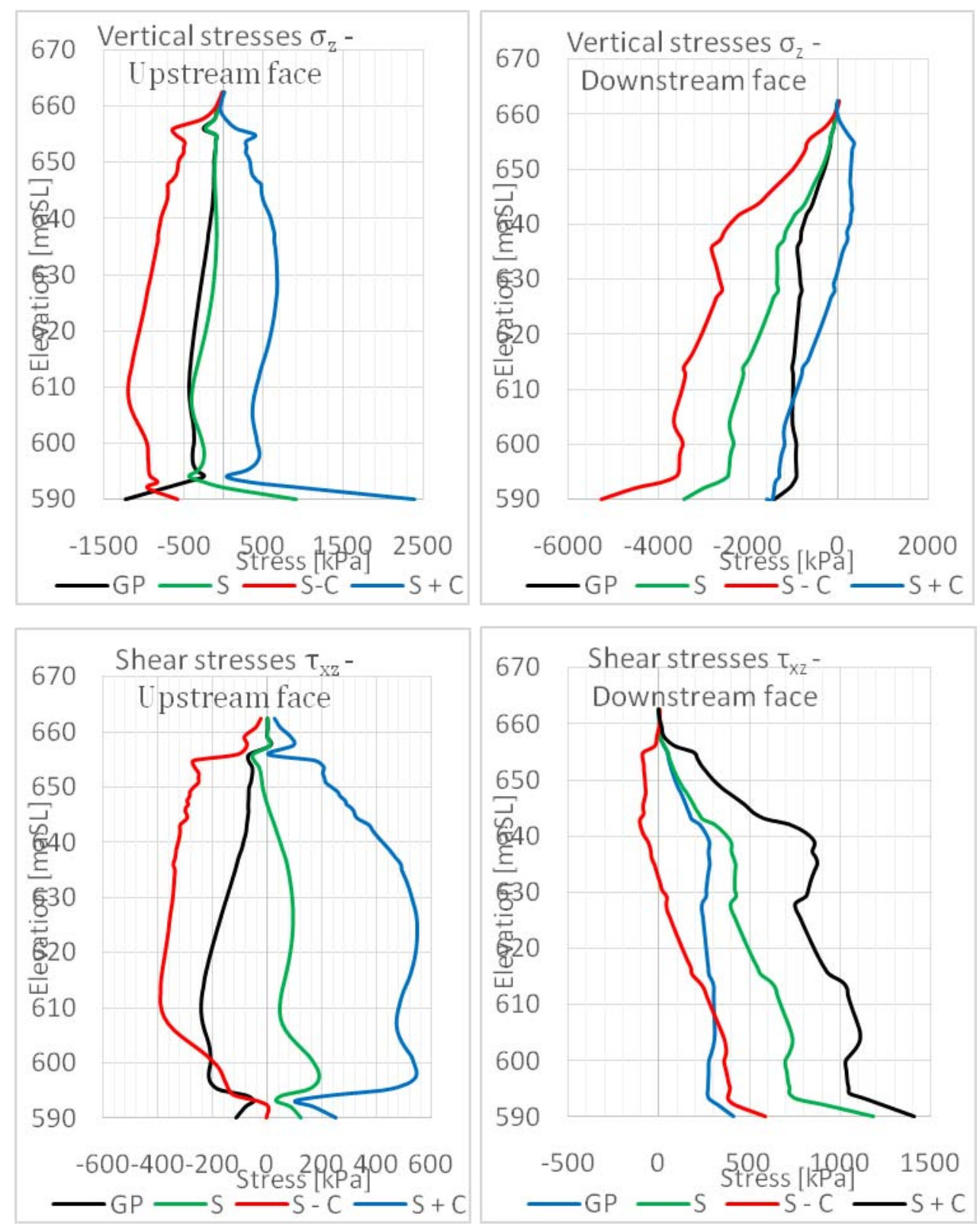

Fig. 9 - Variation of $\sigma_{\mathrm{z}}$ and $\tau_{\mathrm{xz}}$ along the upstream and downstream faces of the dam profile, full reservoir case: GP dead weight,. S-dead weight + hydrostatic pressure including uplift, $\pm \mathrm{C}$-spectral analysis $0.1 \mathrm{~g}$

It can be remarked that vertical stresses $\sigma \mathrm{z}$ due to load combination dead weight + hydrostatic pressure including uplift \pm spectral stresses $0.1 \mathrm{~g}$ vary between $(-1000 \ldots+600) \mathrm{kPa}$ at upstream face and $(-3900 \ldots+300) \mathrm{kPa}$ at downstream face (+ tensile stress).

Shear stresses $\tau \mathrm{Xz}$ directed from downstream to upstream in the dam body at the same load combination reach $500 \mathrm{kPa}$ at upstream face and $1100 \mathrm{kPa}$ at downstream face. 

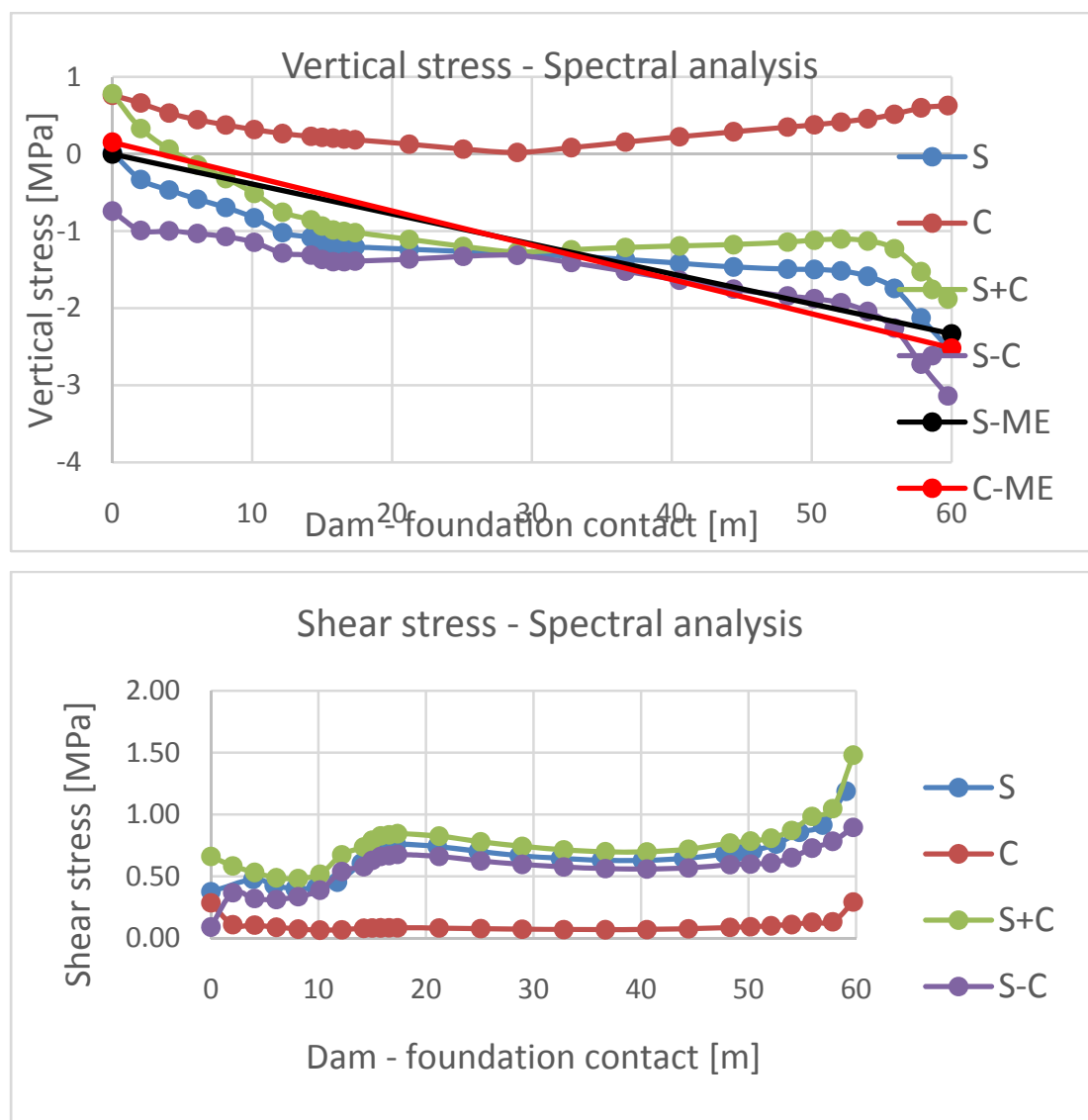

Fig. $10-\sigma_{z}$ and $\tau_{x z}$ diagrams on dam - foundation contact computed in spectral analysis in different hypotheses in full reservoir case $(\mathrm{S}$ - dead weight + hydrostatic pressure + uplift pressure, $\mathrm{C}$ - spectral analysis, ME - elementary method computing stresses + inertia forces computed in compliance with spectral analysis)

Some representative diagram of $\sigma \mathrm{z}$ and $\tau \mathrm{Xz}$ at different hypothesis on dam - foundation contact in full reservoir case are given in Figure 10. The meaning of notations $\mathrm{S}, \mathrm{C}$, was already given, $\mathrm{ME}$ corresponds to elementary method computing stresses + inertia forces computed in compliance with spectral analysis. A satisfactory correlation should be noted between $\sigma \mathrm{z}$ diagram at S-C combination obtained in the spectral analysis and the one obtained by the elementary method.

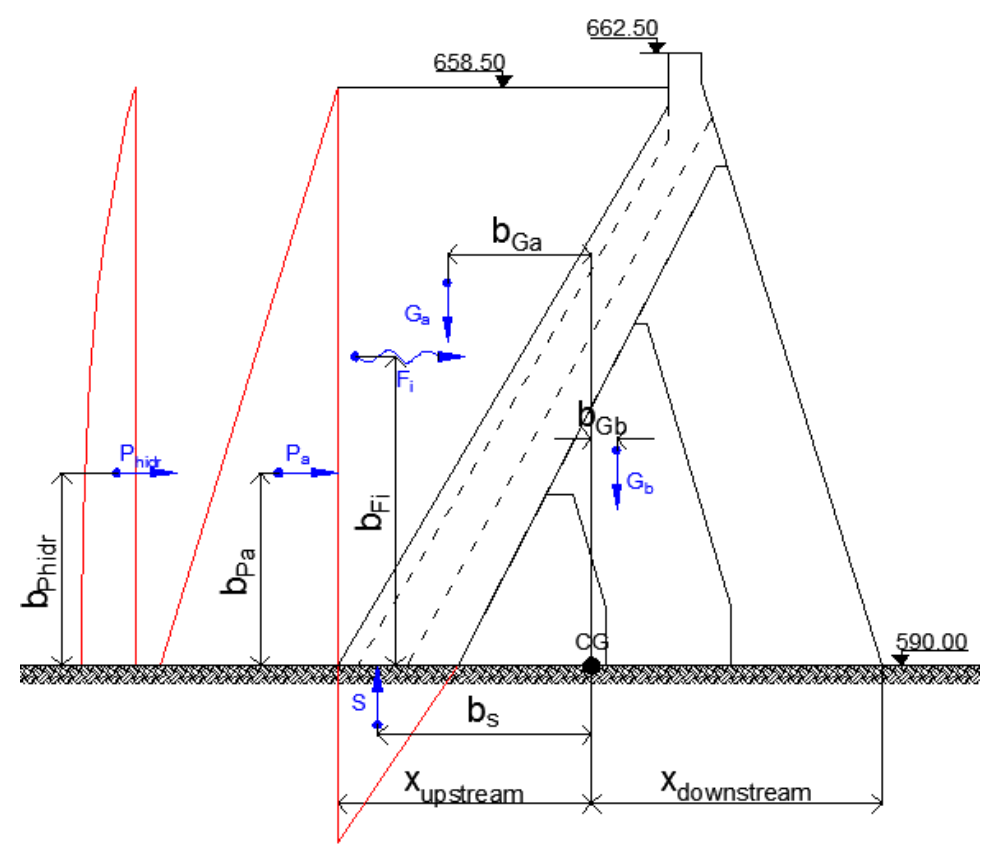

Fig. 11 - Scheme of loads taken into account in the analysis based on strength materials theory (elementary method computing stresses + inertia forces computed in compliance with spectral analysis) 
The loads taken into account in the elementary method based on strength materials theory (eccentric compression calculus) are presented in Figure 11.

The stress state is in allowable limit, taking into consideration the dynamic character of the seismic stresses.

\section{Analysis rtesults by direct time integration}

The main hypotheses accepted in the direct time integration method were already presented at point 3.

Some results obtained in this analysis are illustrated in Figures 12 and 13. The component of the baseline corrected accelerogram having a PGA of $0.1 \mathrm{~g}$ was applied at the finite element mesh bottom on the horizontal upstream - downstream direction.

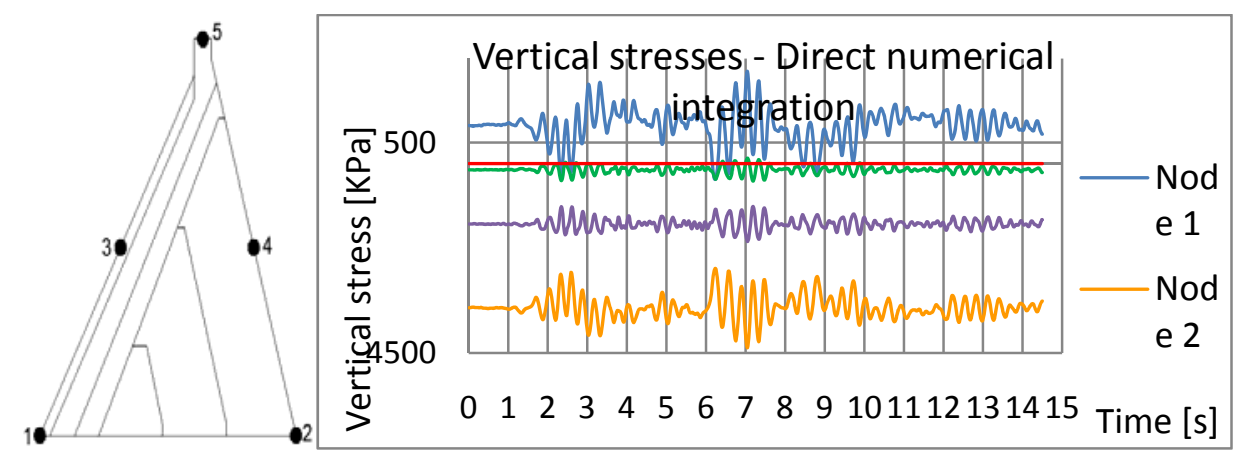

Fig. 12 - $\sigma_{z}$ response time history computed in Direct Time Integration Method due to load's combination of dead weight+hydrostatic pressure+uplift pressure+accelerogram $0.1 \mathrm{~g}$

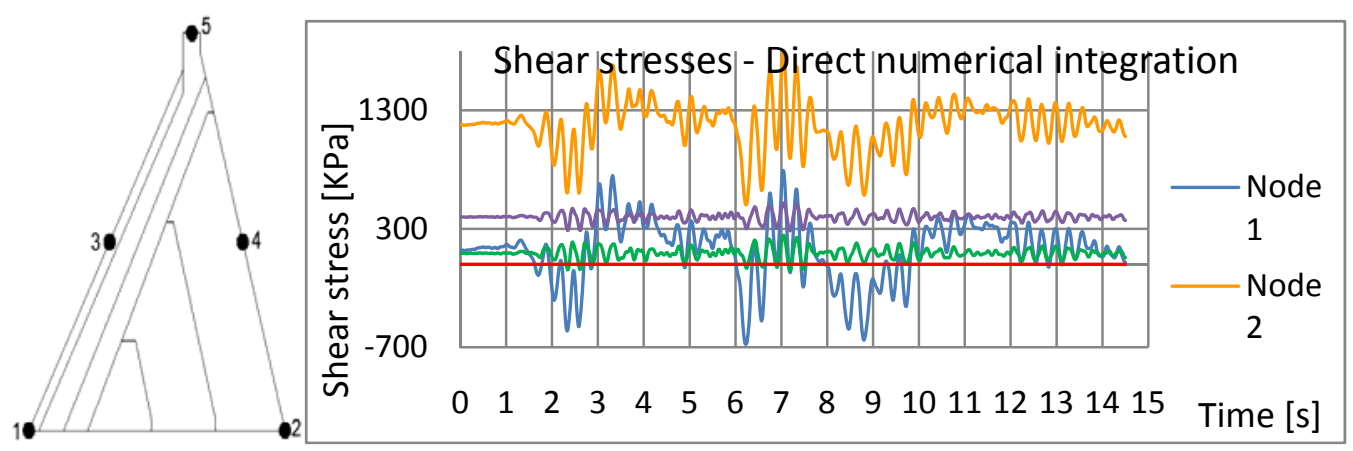

Fig. $13-\tau_{\mathrm{xz}}$ response time history computed in the Direct Time Integration Method due to the load combination of dead weight + hydrostatic pressure+uplift pressure+accelerogram $0.1 \mathrm{~g}$

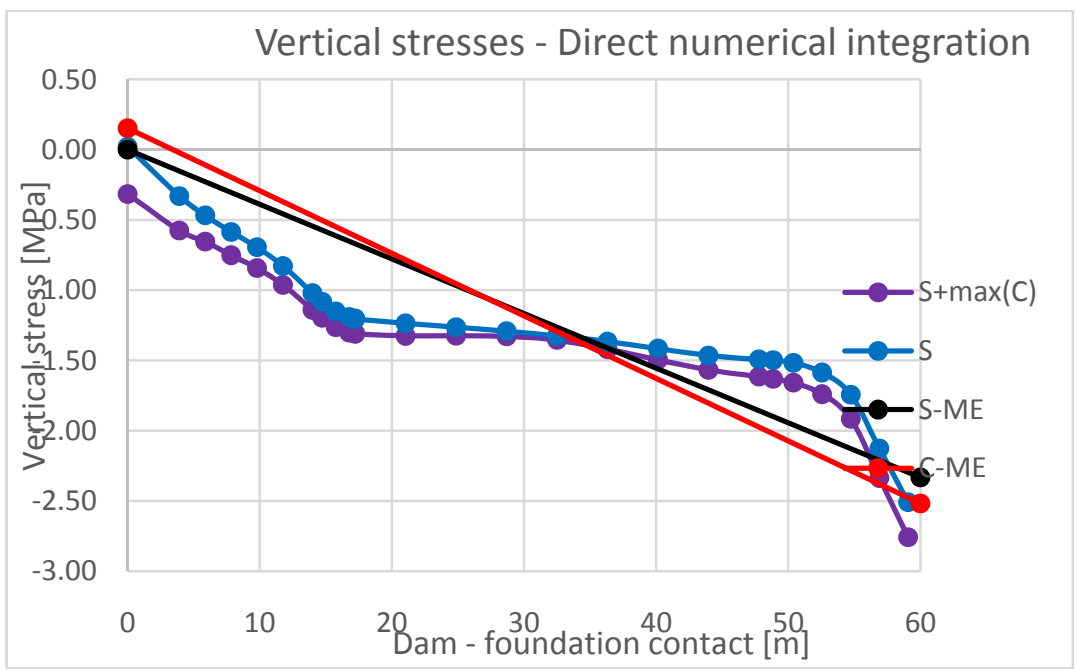




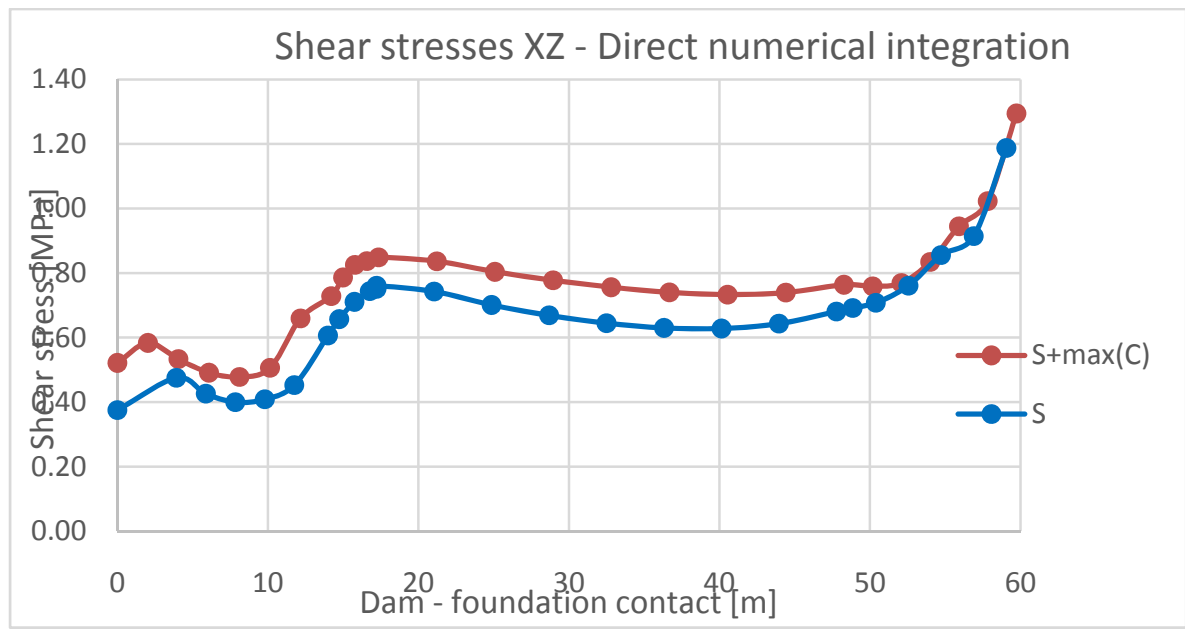

Fig. $14-\sigma_{\mathrm{z}}$ and $\tau_{\mathrm{xz}}$ diagrams on dam - foundation contact computed in direct time integration at combination of dead weight + hydrostatic pressure + uplift pressure+accelerogram $0.1 \mathrm{~g}$ compared with $\sigma \mathrm{z}$ diagram computed by elementary method

In Figures 12 and 13 are presented the response time history in $\sigma \mathrm{z}$ (vertical stress) and $\tau \mathrm{xz}$ (shear stress) in 5 points located in the profile central section due to dead load + hydrostatic pressure including uplift + accelerogram $0.1 \mathrm{~g}$ maximum acceleration. The maximum $\sigma \mathrm{z}$ reaches $378 \mathrm{kPa}$ tension (node 1, upstream toe) and $-2766 \mathrm{kPa}$ compression (node 2, downstream toe). The maximum $\tau \mathrm{xz}$ directed to upstream reaches $1275 \mathrm{kPa}$ (node 2, downstream toe).

The $\sigma \mathrm{z}$ and $\tau \mathrm{xz}$ diagrams on the dam foundation contact computed in direct time integration at the combination of dead weight + hydrostatic pressure + uplift pressure + accelerogram $0.1 \mathrm{~g}$ compared with the $\sigma \mathrm{z}$ diagram computed by the elementary method computing stresses + inertia forces computed in compliance with the spectral analysis are given in Figure 14. The corresponding results obtained by both methods are in satisfactory correlations. Some tensile stresses reaching about $400 \mathrm{kPa}$ resulted in the elementary method at upstream dam toe versus $378 \mathrm{kPa}$ in the direct time integration method. Instead at the downstream dam toe the compression computed in the direct time integration method is higher than in the elementary method $(-2766 \mathrm{kPa}$ versus $-2500 \mathrm{kPa})$.

\section{Comparison of results and concluding remarks}

In order to compare the results of the analyses carried out by the response spectrum method and the direct time integration method some representative results are given in Tables 5 and 6 , respectively in Figure. 15.

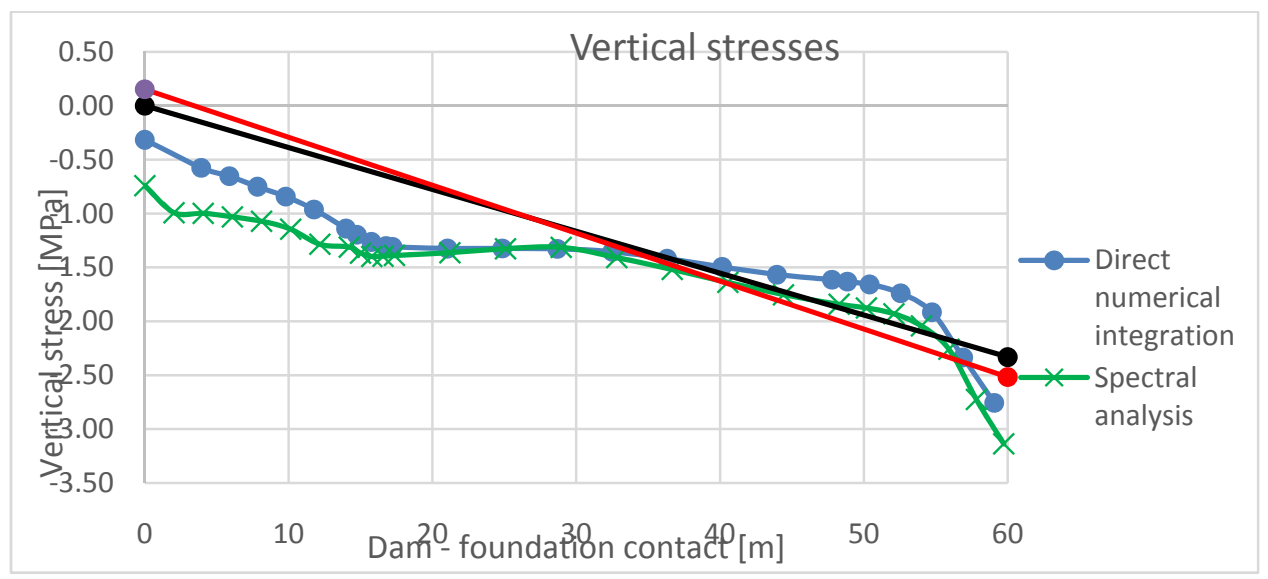




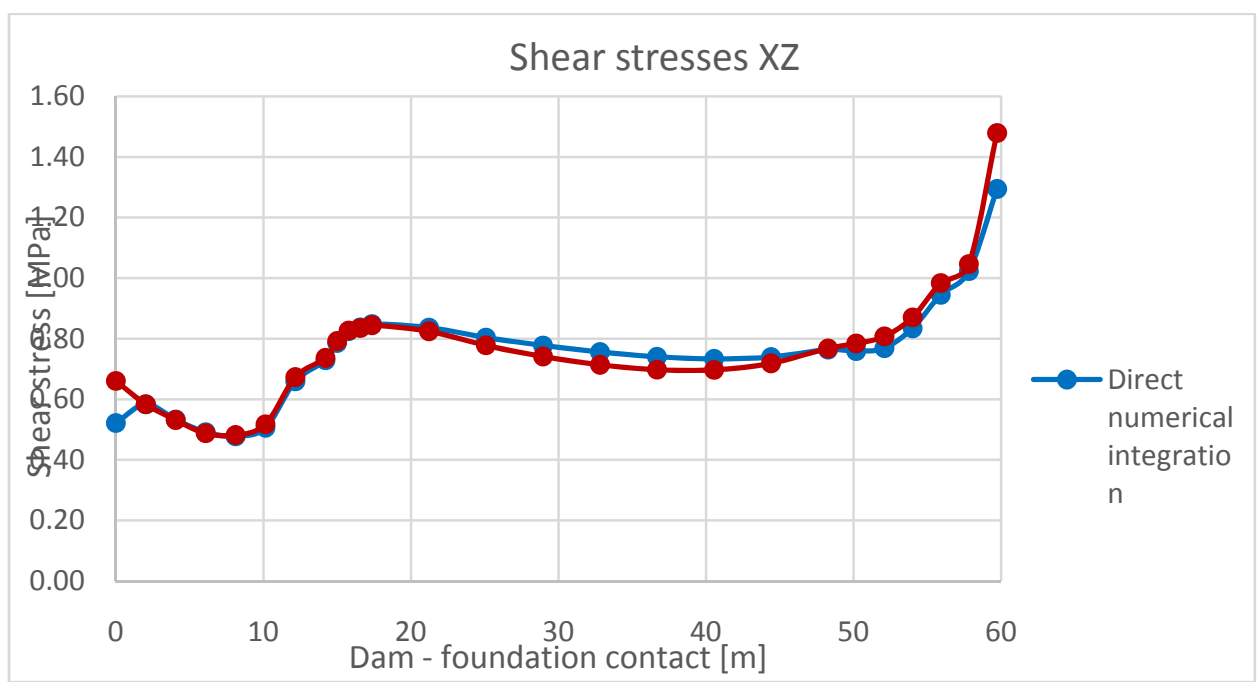

Fig. 15 - Comparative diagrams of $\sigma_{\mathrm{z}}$ and $\tau_{\mathrm{xz}}$ on dam foundation contact, full reservoir case, computed by spectral analysis, direct time integration and elementary method.

Table 5

Vertical stress $-\sigma_{z}$

\begin{tabular}{|c|c|c|c|c|c|c|}
\hline Method & Node & 1 & 2 & 3 & 4 & 5 \\
\hline \multirow{2}{*}{$\begin{array}{l}\text { Direct numerical } \\
\text { integration }\end{array}$} & $\min$ & -316 & -2766 & -414 & -1851 & 0 \\
\hline & $\max$ & 378 & -1865 & 129 & -1021 & 1 \\
\hline \multirow{2}{*}{ Spectral analysis } & $\min$ & -741 & -3138 & -1054 & -3239 & -10 \\
\hline & $\max$ & 782 & -1880 & 606 & -614 & 15 \\
\hline
\end{tabular}

Table 6

Shear stress $-\tau_{\mathrm{xz}}$

\begin{tabular}{|c|c|c|c|c|c|c|}
\hline \multirow{2}{*}{ Method } & Node & 1 & 2 & 3 & 4 & 5 \\
\hline \multirow{2}{*}{ Direct numerical integration } & $\min$ & 283 & 1088 & -54 & 284 & 0 \\
\cline { 2 - 7 } & $\max$ & 461 & 1275 & 245 & 517 & 0 \\
\hline \multirow{2}{*}{ Spectral analysis } & $\min$ & 90 & 896 & -373 & 174 & -25 \\
\cline { 2 - 7 } & $\max$ & 661 & 1479 & 542 & 912 & 2 \\
\hline
\end{tabular}

According to Table 5 the maximum $\sigma z$ compression from dead weight + full reservoir $+0.1 \mathrm{~g}$ horizontal earthquake upstream - downstream combination is at the downstream dam toe (node 2) reaching $-2766 \mathrm{kPa}$ in the direct time integration and $-3138 \mathrm{kPa}$ in the spectral analysis $(13 \%$ difference).

The maximum $\sigma \mathrm{z}$ tension from the same load combination is at the upstream dam toe (node 1) reaching $378 \mathrm{kPa}$ in the direct time integration and $782 \mathrm{kPa}$ in the spectral analysis $(106 \%$ difference). The high difference between the local values may be explained through their small order of magnitude relative to other values that influenced the accuracy of the numerical computation.

According to Table 6 the maximum shear stress $\tau$ xz appears at the downstream dam toe (node 2) reaching $1275 \mathrm{kPa}$ in the direct time integration and $1479 \mathrm{kPa}$ in the spectral analysis $(16 \%$ difference). 
Additionally from Figure 15 one can notice a good correspondence between $\sigma \mathrm{z}$ and $\tau \mathrm{xz}$ stresses computed with the direct time integration and the spectral analysis methods along the dam foundation contact. The values computed by the elementary method are also in satisfactory correlations with their corresponding values obtained in the dynamic analyses.

The comparison between the methods was extended also to the values of the sliding safety coefficient $(\mathrm{k})$ on the dam - foundation contact in the full reservoir hypothesis considering the response to the earthquake action by the spectral method and, by the direct time integration respectively.

In comparison the $\mathrm{k}$ value resulted by the elementary method of calculus was also considered, in compliance with the relation:

$$
\mathrm{k}=\mathrm{f} \frac{\iint_{F A} \sigma_{v}(x, y) d x d y}{\iint_{F A} \zeta_{x z}(x, y) d x d y}=\mathrm{f} \frac{\sum V}{\sum H}
$$

where FA is the dam - foundation area;

$\sigma \mathrm{Z}$ - vertical stresses on the dam - foundation area calculated with the elementary method

$\tau \mathrm{xz}$ - shear stresses on the dam - foundation area calculated with the elementary method

$\Sigma \mathrm{V}$ - sum of the vertical loads acting on dam block

$\Sigma \mathrm{H}$ - sum of the horizontal loads acting on dam block

$\mathrm{f}=0.70$ friction coefficient to sliding on the dam - foundation contact.

The comparison results are summarized in Table 7.

Table 7

\section{Comparison between the methods on the values of the sliding safety coefficient $(k)$}

\begin{tabular}{|c|c|c|c|}
\hline Methods and types of analyses & $\begin{array}{c}\Sigma \mathrm{V} \\
\mathrm{kN}\end{array}$ & $\begin{array}{c}\Sigma \mathrm{H} \\
\mathrm{kN}\end{array}$ & $\begin{array}{c}\mathrm{k} \\
-\end{array}$ \\
\hline $\begin{array}{c}\text { Full reservoir - foundation on stresses } \\
\text { evaluated by FEM ac }=0\end{array}$ & 567010 & 307030 & 1.292 \\
\hline $\begin{array}{c}\text { Full reservoir - foundation on stresses } \\
\text { evaluated by elementary method ac }=0\end{array}$ & 548490 & 345110 & 1.113 \\
\hline Direct time integration ac $=0.1 \mathrm{~g}$ & 500610 & 353260 & 0.991 \\
\hline Spectral analysis ac $=0.1 \mathrm{~g}$ & 430400 & 338900 & 0.889 \\
\hline $\begin{array}{c}\text { Inertia forces evaluated by spectral analysis. } \\
\text { Foundation stresses evaluated by elementary } \\
\text { method ac }=0.1 \mathrm{~g}\end{array}$ & 548490 & 379930 & 1.010 \\
\hline
\end{tabular}

According to the results presented in Table 6 the spectral analysis method is conservative compared with the direct time integration methods concerning the dam sliding stability on the foundation.

Based on the data presented above the followings concluding remarks may be formulated:

- The aim of the paper was to check the accuracy of the results in the dam seismic response provided by the spectral analysis taking into account some doubt on the performance of this method;

- The results in the seismic response of a buttress dam with $73.50 \mathrm{~m}$ maximum height computed by the spectral analysis method were compared with those obtained by the direct time integration. In the comparison corresponding results obtained by the elementary method of analysis were also included (linear distribution of normal stresses). The comparison included the stresses in the representative points of the dam body, dam foundation area and the safety coefficient to sliding on the dam - foundation contact. 
- The conclusion is that both the spectral analysis method and the direct time integration method provided close results, acceptable for engineering use. Generally, the differences between the corresponding values are in the range $0 \ldots .20 \%$, but locally they can reach even $100 \%$ when their order of magnitude is very low relatively to the current values. This may be explained by the accuracy of the numerical computation. As it was expected, the results provided by the spectral analysis method are the conservative ones.

\section{References}

[1]. Priscu, R., Popovici, A.( 1970). Optimisation of gravity and buttress dams (in Romanian), Buletinul Stiintific, I.C.B. nr.4.

[2]. . - Dams in Romania. (2000). Romanian National Committee on Large Dams. Univers Enciclopedic Publishing House, Bucharest.

[3]. ‥ ABAQUS 6.11. (2009). Abaqus / CAE User's Manual. United States of America: Abaqus Inc.

[4]. Popovici, A. (1978). Calculul structurilor hidrotehnice. Analiza dinamică prin metode numerice (204 pagini) I.C.B.

[5]. Popovici, A., Ilinca, C., (Romania), Ayvaz M. T. (Turkey). (2013). The performance of the neural networks to model some response parameters of a buttress dam to environment actions 9-th ICOLD European Club Symposium, Venice.

[6]. Kashima, T., Kondo, M., Enomura, Y., Sasaki, T. (2014). Effects of reservoir water level and temperature on vibration characteristics of concrete gravity dam. International Symposium on Dams in a Global Environmental Challenges, Bali-Indonesia.

[7]. Meghella, M., Furgani, L. (2014). Nonlinear seismic analysis of dams. International Symposium on Dams in a Global Environmental Challenges, Bali-Indonesia.

[8]. Ito, T., Sasaki, T., Yamaguchi, Y., Annaka, T. (2014).Attenuation relationship of earthquake motion at dam foundation in consideration of the 2011 Tohoku earthquake. International Symposium on Dams in a Global Environmental Challenges, Bali-Indonesia 